\title{
Reflections on richness and complementarity in diversity: The Tuning Journal contribution to global education and scholarship
}

\author{
Mary Gobbi \\ Editor
}

doi: http://dx.doi.org/10.18543/tjhe-7(1)-2019pp25-30

Since its inception, one of the objectives of the Tuning Journal for Higher Education is to provide a platform whereby a range of Higher Education stakeholders "across societies, cultures, professions, and academic disciplines' can 'engage in constructive debate on new approaches, methods and tools on teaching, learning and assessment in competence-based and student centred curricula in higher education." (Objective 2)

As the incoming editor, experiencing my 'first edition', I have observed and reflected upon what this particular objective might mean for authors, reviewers, editors and readers. I propose to dissect Objective 2 so as to highlight the riches and tensions embedded within the Journal as a direct consequence of the laudable ambitions of Objective 2.

Broadly speaking, the factors listed within Objective 2 represent the influences of discipline / profession, society, research and education upon the individual author or reviewer as summarized in Table 1.

Table 1

Objective 2: Influencing factors experienced by the author / reviewer

\begin{tabular}{|l|l|l|}
\hline \multicolumn{1}{|c|}{ Influencing factors } & \multicolumn{2}{c|}{ Continuum Tendency } \\
\hline Subject discipline & Bounded discipline & $\begin{array}{l}\text { Unbounded, interdisciplinary } \\
\text { or emergent discipline }\end{array}$ \\
\hline $\begin{array}{l}\text { Nature of the } \\
\text { discipline }\end{array}$ & $\begin{array}{l}\text { a) Science and } \\
\text { mathematics } \\
\text { b) Non- human } \\
\text { discipline }\end{array}$ & $\begin{array}{l}\text { a) Arts and humanities } \\
\text { b) Human /person- based } \\
\text { discipline }\end{array}$ \\
\hline
\end{tabular}

1 "Focus and Scope," Editorial Policies (Tuning Journal for Higher Education), Tuning Academy, accessed November 16, 2019, http://www.tuningjournal.org/about/editorialPolicies \#focusAndScope. 


\begin{tabular}{|c|c|c|}
\hline Influencing factors & \multicolumn{2}{|c|}{ Continuum Tendency } \\
\hline Profession & $\begin{array}{l}\text { a) Regulated } \\
\text { b) Established }\end{array}$ & $\begin{array}{l}\text { a) Unregulated } \\
\text { b) Emergent or semi } \\
\text { profession }\end{array}$ \\
\hline $\begin{array}{l}\text { Writing style / } \\
\text { Voice }\end{array}$ & $\begin{array}{l}\text { Expects or normalises } \\
\text { a) third person } \\
\text { b) detachment } \\
\text { c) single /privileged } \\
\text { voice } \\
\text { d) passive writing }\end{array}$ & $\begin{array}{l}\text { Encourages or Permits: } \\
\text { a) first person: singular or } \\
\text { plural } \\
\text { b) reflexivity } \\
\text { c) multiple perspectives/voices } \\
\text { d) rhetorical speech } \\
\text { e) mixed genres } \\
\text { f) non-discriminatory writing } \\
\text { c) active writing }\end{array}$ \\
\hline \multicolumn{3}{|c|}{ Societal influences } \\
\hline International reach & Nationally bound & International /globalising \\
\hline $\begin{array}{l}\text { Society and } \\
\text { Systems of } \\
\text { governance }\end{array}$ & Totalitarian, autocratic & $\begin{array}{l}\text { Primarily democratic/ } \\
\text { participatory }\end{array}$ \\
\hline Culture and context & De-contextualised & $\begin{array}{l}\text { Contextualised \& sensitive to } \\
\text { culture }\end{array}$ \\
\hline \multicolumn{3}{|c|}{ Research influences } \\
\hline Research methods & Single method & Multiple /mixed methods \\
\hline $\begin{array}{l}\text { Research strategies } \\
\text { or paradigms }\end{array}$ & $\begin{array}{l}\text { Quantitative, objective } \\
\text { and positivist }\end{array}$ & Qualitative, experiential \\
\hline \multicolumn{3}{|c|}{ Educational influences } \\
\hline $\begin{array}{l}\text { Educational } \\
\text { framework }\end{array}$ & $\begin{array}{l}\text { a) Teacher, subject or } \\
\text { institutionally lead } \\
\text { b) National curricula } \\
\text { c) Restricted } \\
\text { stakeholders } \\
\text { d) Internal review }\end{array}$ & $\begin{array}{l}\text { a) Student centred } \\
\text { b) Locally based curricula } \\
\text { c) Stakeholder engagement } \\
\text { d) External review }\end{array}$ \\
\hline $\begin{array}{l}\text { Educational } \\
\text { approach }\end{array}$ & $\begin{array}{l}\text { a) Input /content } \\
\text { driven } \\
\text { b) Didactic tendencies }\end{array}$ & $\begin{array}{l}\text { a) Outcome or competence } \\
\text { based } \\
\text { b) Participatory }\end{array}$ \\
\hline
\end{tabular}

By definition, strongly bounded disciplines and professions have their own discursive strategies, writing genres, methodological preferences, prescribed formats and epistemological assumptions. In addition, their 
associated Journals have different citation requirements (e.g. Publication Manual of the American Psychological Association, Chicago Manual of Style, Harvard, Vancouver or a specified hybrid) and language specifications. This means many contributors (including me) are learning a new citation system when submitting or first reviewing for the Journal. As we know, old habits can 'die hard'! Given the superb and authentic global reach of the Journal, some contributors are handling English as a second language. The publication struggles experienced by non -native speakers, particularly with the dominance of Anglophone publications, are well documented. ${ }^{2,3,4}$ Currently, the Journal enables submissions in English (UK and US style).

For a given individual, the overall impact may be complex with not all the influencing factors resting at one extreme of the continua outlined in Table 1. What is crucial, however, is how these background influences shape the nature, genre, discourse and presentation of the written submission to the Journal. Similarly, reviewers and readers come from their own traditions with accompanying expectations. Hence, a reviewer may provide feedback from their own disciplinary tradition that is at odds with that normally experienced by the author. A classical instance is the use of the third person versus the critically reflective use of the first person often employed by qualitative researchers, or the active voice as advocated by the British Medical Association in their guidelines to authors. As the Journal evolves further, our ability to be comfortable with the appropriate use of these different styles will facilitate accessibility. Occasionally, the use of the first person generates inappropriate description rather than analytical insights and reflexivity. Fortunately, as Lupo and Anna reported, so far we have had little need to resort to a third reviewer. No doubt this has been aided by the use of assistant editors and reviewers familiar with Tuning and the contexts of the submissions.

The beauty of the Tuning Journal for Higher Education is that it welcomes diversity and, by definition, not only a range of genres, but mixed genres. The scope of the ever-widening international Tuning community has enabled opportunities for reflection, educational reform, development and innovation.

2 Theresa Lillis and Mary Scott, "Defining academic literacies research: issues of epistemology, ideology and strategy," Journal of Applied Linguistics 4, no. 1 (2007): 5-32.

3 Safnil Arsyda, "Struggling for International Publication: The Potential Rhetorical Problems for Indonesian Scholars in Social Sciences and Humanities when Writing in English," Advances in Social Science, Education and Humanities Research, 301 (2018): 469-478.

${ }^{4}$ Lucia Thesen and Linda Cooper, eds., Risk in Academic Writing, Post graduate Students, their Teachers and the Making of Knowledge. New Perspectives on Language Education (Printed: Bristol for Multilingual Matters, 2013). 
The Journal forms a natural home for the dissemination of these initiatives. As Lupo and Anna outlined, eighty geographical contexts/situations were represented during their tenure as editors. While this is most impressive, it demands particular skills from reviewers and authors alike. Authors need to make their contextual situation transparent so that readers and reviewers can experience the 'taken for granted' elements embedded in their context. Similarly, reviewers have to discern whether something is truly 'innovative' or 'new' or simply replication.

Let me give an example. When a new technology is first adopted as a pedagogical tool, it is 'novel'; the application may be 'innovative' and the outcomes variable depending upon the efficacy of the intervention and the appropriateness for the learners concerned. With the passage of time, this new educational tool gets embedded within one region of the world - perhaps within a single discipline. Research is conducted and the tool evaluated with generally positive outcomes (e.g. student learning, experience, achievement or resource efficiency). The challenges that now arise are the extent to which this intervention works with different types of students and their teachers in different settings. Sensible educators would test the introduction of tools which are novel to their setting, even if they are established and embedded elsewhere. Crucially, the study needs to point out the similarities and differences between the original setting and the applied setting to enable the reader to establish the relevance of the study to an international audience and their own domestic context. Here the Journal can play a key role in publishing our equivalence of 'translation' research, but only in so far as authors critically reveal the cultural nuances or characteristic features of the setting concerned.

The Tuning Journal is open to both subject experts, seeking to improve their practical pedagogy, and those whose subject expertise is education with or without a core academic discipline. Once again, we see the potential tensions that arise from these different discourses and expectations. Perhaps Boyer's seminal model of scholarship, comprising four domains, namely discovery, integration, application and teaching, has particular resonance for the Journal. ${ }^{5}$ Our scope of interest enables those who desire to publish through the scholarship of discovery to reveal their experiences and findings through primary research and investigation. The integration scholars provide us with the possible meanings and interpretation behind educational activities

${ }^{5}$ Ernest L Boyer, Scholarship Reconsidered: Priorities of the Professoriate, Special Report (Stanford: The Carnegie Foundation for the Advancement of Teaching, 1990), http:// www.hadinur.com/paper/BoyerScholarshipReconsidered.pdf. 
and developments. The scholarship of application appeals to those who seek answers to practical problems, questioning how theory or new technology applies to this situation or that student. Finally, in the scholarship of teaching, the focus is on the role of the teacher and the way each teacher can enhance the achievements and experiences of their students through learning to evaluate and analyze the work of others as well as their own daily practice as a teacher. Good research papers of course give some attention to all the domains of Boyer.

In the first edition of the Journal in 2013, Paul Ryan, the founding editor, acknowledged the contributions made by the European Commission and the Journal hosts, the Universities of Deusto (Spain) and Groningen (The Netherlands). Paul laid down the gauntlet and invitation, namely that the Journal was to be open to all those "working to improve the quality, transparency, transferability and relevance of higher education programmes and who wish to share their experience with the global community". ${ }^{6}$

The progress so far with the Journal has more than justified the Spirit evoked by the European Bologna Process and the key role played by the Tuning founders and activists in their endeavor to enable Higher Education Institutions to address the challenges of this Century. They have helped contribute to the necessary reforms of the European Higher Education Space. Tuning commenced with aspirations to facilitate student centred learning underpinned by effective pedagogy, stakeholder engagement and the achievement of quality assured competence-based education. What is crucial in the Tuning vision, particularly as it is now literally sharing experience within the global community, is the commitment to avoid uniformity, celebrate diversity, recognize points of convergence and find opportunities to share good practices. In true academic fashion, we must be ever ready for debate and deliberation.

However, the sharing of our experiences through the medium of text means that our debates must focus on how to achieve some degree of equivalence in academic rigour. This rigour must be robust enough to cross different disciplines, cultures and contexts while respecting individuality, identity and institutions. While it is essential to make explicit the common reference points associated with international codes of ethical publishing, research and educational conduct, some degree of flexibility may be required in the way we evaluate different modes of writing, argumentation, structure and presentation so as to be sensitive to culture and context. In other words,

${ }^{6}$ Paul D. Ryan, "Editorial," Tuning Journal for Higher Education 1, no. 1 (November 2013): 13, http://www.tuningjournal.org/article/view/17/4. 
we need to continue to learn from, and with, one another about what constitutes quality in our different domains, what variations are acceptable and what modes of presentation must be achieved.

The very success of the Journal, the Tuning Process and the welcome contributions of the wider higher education community has led to this critical reflection on how we develop further a truly global publishing endeavor without experiencing, or generating, blind uniformity, inappropriate hegemony and unconscious bias.

So, in conclusion, the door is open for further critical debate and articles that address this challenge. 


\title{
Reflections on richness and complementarity in diversity: The Tuning Journal contribution to global education and scholarship
}

\author{
Mary Gobbi
}

Editor

doi: http://dx.doi.org/10.18543/tjhe-7(1)-2019pp25-30

\section{Copyright}

Copyright for this article is retained by the Publisher. It is an Open Access material that is free for full online access, download, storage, distribution, and or reuse in any medium only for noncommercial purposes and in compliance with any applicable copyright legislation, without prior permission from the Publisher or the author(s). In any case, proper acknowledgement of the original publication source must be made and any changes to the original work must be indicated clearly and in a manner that does not suggest the author's and or Publisher's endorsement whatsoever. Any other use of its content in any medium or format, now known or developed in the future, requires prior written permission of the copyright holder. 